\title{
Comparison of two approaches for measuring household wealth via an asset-based index in rural and peri-urban settings of Hunan province, China
}

\author{
Julie Balen ${ }^{1,2,3,4^{*}}$, Donald P McManus', Yue-Sheng Li ${ }^{1,5}$, Zheng-Yuan Zhao ${ }^{5,6}$, Li-Ping Yuan ${ }^{5}$, Jürg Utzinger ${ }^{7,8}$, \\ Gail M Williams², Ying Li $i^{5}$, Mao-Yuan Ren ${ }^{5}$, Zong-Chuan Liu' ${ }^{5}$ Jie Zhou' ${ }^{5}$, Giovanna Raso ${ }^{1,2,7,8,9}$
}

\begin{abstract}
Background: There are growing concerns regarding inequities in health, with poverty being an important determinant of health as well as a product of health status. Within the People's Republic of China (P.R. China), disparities in socio-economic position are apparent, with the rural-urban gap of particular concern. Our aim was to compare direct and proxy methods of estimating household wealth in a rural and a peri-urban setting of Hunan province, P.R. China.

Methods: We collected data on ownership of household durable assets, housing characteristics, and utility and sanitation variables in two village-wide surveys in Hunan province. We employed principal components analysis (PCA) and principal axis factoring (PAF) to generate household asset-based proxy wealth indices. Households were grouped into quartiles, from 'most wealthy' to 'most poor'. We compared the estimated household wealth for each approach. Asset-based proxy wealth indices were compared to those based on self-reported average annual income and savings at the household level.
\end{abstract}

Results: Spearman's rank correlation analysis revealed that PCA and PAF yielded similar results, indicating that either approach may be used for estimating household wealth. In both settings investigated, the two indices were significantly associated with self-reported average annual income and combined income and savings, but not with savings alone. However, low correlation coefficients between the proxy and direct measures of wealth indicated that they are not complementary. We found wide disparities in ownership of household durable assets, and utility and sanitation variables, within and between settings.

Conclusion: PCA and PAF yielded almost identical results and generated robust proxy wealth indices and categories. Pooled data from the rural and peri-urban settings highlighted structural differences in wealth, most likely a result of localized urbanization and modernization. Further research is needed to improve measurements of wealth in low-income and transitional country contexts.

\section{Introduction}

Poverty and people's health status are intimately connected, yet the relationship between them is complex and bi-directional $[1,2]$. On one hand, ill-health may lead to economic poverty [1], or a decrease in expendable income due to high medical bills and/or via a direct reduction, or loss, of wages throughout an illness

\footnotetext{
* Correspondence: julie.balen@lshtm.ac.uk

'Queensland Institute of Medical Research, P.O. Royal Brisbane Hospital, Brisbane 4029, Queensland, Australia

Full list of author information is available at the end of the article
}

[3]. On the other hand, poor health may result from poverty [1], including an inability to afford adequate nutrition, sanitation, housing, education and healthcare, and poverty-related lifestyle factors that increase disease risk and/or decrease access to medical facilities and services $[4,5]$. In the People's Republic of China (P.R. China), rapid economic growth and human development over the past three decades has brought over 300 million people out of poverty (arbitrarily defined as living on less than US\$ 1 per day) and has vastly improved the overall health status of the population [6]. However, it
C Biomed Central 
has also affected the course of income distribution such that disparities in socio-economic position (SEP; for a definition, see Appendix) are currently among the most important social policy issues in the country [7]. Inequalities appear to be widening both across and within different provinces in P.R. China, with the ruralurban gap of particular concern [7]. Since SEP is an important determinant of health, it is conceivable that such disparities will lead to large gaps in health care provision within P.R. China [8]. In order to plan, implement and monitor health programs and other publicly or privately provided services in an equitable way, it is necessary to identify the poor, including individuals or households with low SEP, who might be more vulnerable to poor health outcomes [5].

While SEP can be measured on multiple levels [1], in the past it was mostly determined using an individual's education level, sometimes in combination with their occupation. Currently, approaches for measuring household SEP include 'direct' measures of economic status, including (i) income, (ii) expenditure, and (iii) financial assets (e.g., savings and pensions), and 'proxy' measures (e.g., household durable assets (Appendix), housing characteristics and access to utilities and sanitation) developed from the wealth index originally proposed by Rutstein in the mid-1990 s [9]. Direct measurements can be expensive to collect and may require complex statistical analyses that are beyond the scope of many population health studies [5,10-12]. In developing country settings in particular, large seasonal variability in earnings and a high rate of self-employment, together with potential recall bias and false reporting, may render such data inaccurate or even unreliable [10]. Proxy measures are thought to be more reliable, since they require only data collected using readily available household questionnaires supported by direct observation. A study carried out in southeast Nigeria, however, questioned whether proxy measures are indeed more reliable than direct measurements [11]. From a public health point of view, the proxy wealth index approach is more useful than that of direct measures, since it explains the same, or a greater, amount of the differences between households on a set of health indicators than an income/expenditure index, while requiring far less effort from respondents, interviewers, data processors and analysts [10]. Additionally, proxy measures might be more accurate approximations of SEP, as they measure financial stock ('permanent income') rather than flow ('current income'), and hence are less prone to fluctuation [10,12-14].

Due to the large volume of potentially redundant asset data produced, a data reduction technique known as exploratory factor analysis is often utilized. Exploratory factor analysis evaluates the most meaningful basis to re-express a large, pre-determined set of variables, exploring the relationships between them and filtering out noise to reveal indicators that map most strongly to an underlying latent structure. Two common methods of extracting that structure are principal components analysis (PCA; Appendix) and principal axis factoring (PAF; Appendix), which describe variation among the observed variables via a set of derived uncorrelated variables referred to as principal components (PCs) or principal factors (PFs), respectively [15]. Although these two methods often yield similar results, the former is preferred as a method for data reduction, while the latter is widely used for detecting structure within the data. Previously, studies have used either PCA or PAF but comparisons between these two approaches are rare. Based on the inter-relationship between the set of variables, exploratory factor analysis also assigns weights to ownership of the assets. The weights correspond to the factor loadings (eigenvectors; Appendix) of the first derived variable, and are used to generate an index of relative SEP. Using weights derived through exploratory factor analysis may be a more appropriate method of assigning weights to the variables than the more simplistic equal weights method, the complex weighted-by-price-of-item approach or on an ad-hoc basis [16].

Few studies have attempted to verify the extent to which the asset-based index approach is a good proxy for household economic wealth. Concerns include the handling of publicly provided goods and services, and the direct effects of the indicator variables that make up indices, as well as ways of adjusting for household size and age-composition $[17,18]$. The increasingly widespread use and application of proxy measurements of household economic wealth and SEP, and growing use of exploratory factor analysis, in public health studies calls for further research in this area, particularly in low-income settings and transitional countries.

Here we report the application of exploratory factor analysis to household data that were collected during a survey of parasitic infections in Hunan province, P.R. China. Our aim was to calculate and examine assetbased proxy wealth indices generated by PCA and PAF, and to compare them to other measures of wealth based on purely economic variables, including self-reported annual household income and savings. Results are reported for a rural and a peri-urban (Appendix) setting and aggregated between the two.

\section{Methods}

\section{Study area and population}

The study was carried out in two villages; namely (i) Wuyi, in Hanshou county, southern Dongting Lake area, and (ii) Laogang, in Yueyang county, eastern Dongting Lake area. Both villages are located in Hunan province. The surveys were conducted between November and December 2006. The villages were selected on the basis 
of previous studies investigating the epidemiology of parasitic infections, including schistosomiasis [19]. Wuyi is situated in a rural area, whereas Laogang is periurban, located on the outskirts of Yueyang, the major city in the Dongting Lake region. All individuals from both villages were invited to participate in the study.

\section{Field procedures}

Senior personnel from two local schistosomiasis control stations were involved in co-ordinating the study. Basic demographic information was obtained from a census performed one year previously in both villages. The questionnaire was translated into Mandarin Chinese, back-translated into English, pre-tested in a nearby village and readily adapted to the local setting. It was administered to the heads of households, and included questions on household demographics, the number of wage earners and non-wage earners, annual household income (7 categories: <500; 500-1999; 2000-4999; 50009999; 10,000-29,999; 30,000-49,999; $\geq 50,000 \mathrm{CNY}$ ) and savings ( 6 categories: <500; 500-699; 700-999; 1000 1499 ; $1500-1999$; $\geq 2000 \mathrm{CNY}$ ), the primary and secondary sources of income, ownership of 22 household durable assets (e.g., color TV, washing machine, air conditioner, etc.), 10 housing characteristics (e.g., floor material, wall material, roof material, etc.) and six utility (Appendix) and sanitation variables (e.g., tap water, toilet in house, etc.).

Interviewers were familiar with the local setting and dialect and were acquainted with qualitative methods. The head of each household was invited to respond to the questions; if the household head was absent on the day of interview, the interviewer returned to that residence the following day, for up to a period of 14 days, after which the next of kin was asked to respond.

\section{Consent and ethical approval}

Ethical clearance for this study was obtained from the Medical Ethics Committee of Hunan province and Queensland Institute of Medical Research. Village authorities were informed about the aims and procedure of the study and provided written informed consent. Oral informed consent was obtained from each individual.

\section{Data management and statistical analysis Data management}

Data were double-entered into a bilingual Microsoft ${ }^{\oplus}$ Access 2002 database, cross-checked and subsequently analyzed with SPSS version 16.0 (Illinois, USA).

\section{Socio-economic data and asset ownership}

Household income and savings data were equivalized to adjust for household needs based upon the number of household members (per-capita) and a combination of number and age (per-adult, defined as individuals aged $>16$ years). This was done using the median value of each income or savings band and dividing by the number of members or adult members per household. Annual per-capita income and per-adult income, primary source of income, ability to save (yes or no binary variable) and annual per-capita and per-adult savings were then examined using a $\chi^{2}$ test. The Student's $t$-test statistic was used to compare the mean age and mean household size between the two villages. A stepwise multinomial logistic regression analysis with annual percapita income bands as the dependent variable and ownership of household durable asset as independent binary covariates was used to test the association between household income and asset ownership within each setting separately and for the pooled data from both villages. Covariates were included at a significance level of $<0.2$. Covariates that were not significantly associated with income were removed in a stepwise backward elimination process. Adjusted odds ratios (OR) and 95\% confidence intervals $(\mathrm{CI})$ were computed for associations with p-values $<0.05$.

\section{Construction of asset-based proxy wealth indices using PCA and PAF}

A detailed protocol of how we constructed asset-based proxy wealth indices is given in the Additional File. In brief, the binary data on household durable assets, housing characteristics and utility and sanitation variables were organized into a matrix with $m$ households as rows (where $m_{\text {rural }}=258$ and $\left.m_{\text {peri-urban }}=246\right)$ and $n$ variables as columns. The initial $n=38$-item correlation matrices for each setting were examined for internal consistency (Table 1). To enable the matrix to be factorable, only variables with sufficient correlation $(\phi>|0.3|)$ with at least three other variables were included in further analyses. If any variable correlated highly $(\phi>\mid$ $0.8 \mid$ ) with other variables, only one variable from the group of correlated variables was arbitrarily selected and included in further analyses, to avoid multicollinearity. Factorability of the $m$ by $n$ matrices was determined using Bartlett's test of sphericity (Appendix) and the Kaiser-Meyer-Olkin (KMO) test (Appendix). Variables were excluded in a stepwise manner until a factorable $m$ by $n$ correlation matrix with a KMO $>0.7$ was reached, for each village separately. Diagonal and off-diagonal values of the anti-image correlation matrix (Appendix) were used to assess the sampling adequacy.

Next, components and factors were extracted from each of the final two correlation matrices using PCA and PAF, respectively. Components and factors, respectively, were extracted without and with rotation (Appendix) and the best method was selected according to the maximum squared factor loadings and the relative simplicity of the model. In each case, eigenvalues $>1$ 
Table 1 Demographic variables of the respondents in a household-based questionnaire survey in rural (Wuyi village) and peri-urban (Laogang village) settings of Hunan province, China

\begin{tabular}{|c|c|c|c|c|}
\hline Demographic variable & $\begin{array}{c}\text { Rural } \\
(\mathrm{n}=258)(\%)\end{array}$ & $\begin{array}{c}\text { Peri-urban } \\
(n=246)(\%)\end{array}$ & $\chi^{2}$ & $p$-value \\
\hline \multicolumn{5}{|l|}{ Sex } \\
\hline Male & $204(79.1)$ & $142(57.7)$ & & \\
\hline Female & $54(20.9)$ & $104(42.3)$ & 27.4 & $<0.001$ \\
\hline \multicolumn{5}{|l|}{ Head of household } \\
\hline Yes & $207(80.2)$ & $167(67.9)$ & & \\
\hline No & $51(19.8)$ & $79(32.1)$ & 10.0 & 0.002 \\
\hline \multicolumn{5}{|l|}{ Age (years) } \\
\hline Mean $(\mathrm{SD})^{1}$ & $48.9(12.3)$ & $51.0(12.6)$ & & \\
\hline \multicolumn{5}{|l|}{ Household size } \\
\hline 1 individual & $17(6.6)$ & $24(9.8)$ & 1.7 & 0.194 \\
\hline 2 individuals & $101(39.2)$ & $97(39.4)$ & 0.0 & 0.948 \\
\hline 3 individuals & $71(27.5)$ & 95 (38.6) & 7.0 & 0.008 \\
\hline$\geq 4$ individuals & $69(26.7)$ & $30(12.2)$ & 16.9 & $<0.001$ \\
\hline Mean household size $(S D)^{2}$ & $2.9(1.3)$ & $2.6(1.0)$ & & \\
\hline \multicolumn{5}{|l|}{ Number of earners/household } \\
\hline No earners & $5(1.9)$ & $3(1.2)$ & 0.4 & 0.519 \\
\hline 1 earner & $30(11.6)$ & 77 (31.3) & 29.1 & $<0.001$ \\
\hline 2 earners & $190(73.7)$ & $146(59.4)$ & 11.6 & 0.001 \\
\hline 3 earners & $16(6.2)$ & $15(6.1)$ & 0.0 & 0.961 \\
\hline$>4$ earners & $17(6.6)$ & $5(2.0)$ & 6.3 & 0.012 \\
\hline Mean household size per number of earner $(S D)^{3}$ & $1.5(0.7)$ & $1.6(0.8)$ & & \\
\hline
\end{tabular}

${ }^{1} t$-test statistic $=-1.9$, d.f. $=492, \mathrm{p}=0.062$

${ }^{2} t$-test statistic $=3.0$, d.f. $=502, p=0.003$

${ }^{3} t$-test statistic $=-1.9$ d.f. $=494, \mathrm{p}=0.054$

(Appendix), examination of the scree plots and the cumulative proportion of variance explained by each component or factor were taken as criteria for extraction. For simplicity, a cut-off eigenvector $>|0.3|$ was used to signify component or factor loadings of interest and, where variables loaded equally on more than one component or factor, the Cronbach's coefficient $\alpha$ (Appendix) was used to select the component or factor on which to place the variable.

The PC and PF loadings were used to compute standardized indices of relative household wealth within each village, according to the following equation:

$$
A_{i}=\hat{\gamma}_{1} \alpha_{i 1}+\ldots+\hat{\gamma}_{k} \alpha_{i k}
$$

where $\alpha_{i k}=\left(x_{i k}-\bar{x}_{k}\right) / s_{k}$

such that $A_{i}$ is the standardized asset index score per household $i$, the ${ }_{k} \mathrm{~s}$ are the factor loadings or weights of each asset $k$, estimated by either PCA or PAF, and the $\alpha_{i k} \mathrm{~s}$ are the standardized values of asset $k$ for household $i$ (i.e., $x_{i k}$ is the ownership of asset $k$ by household $i$, where 0 represents not owning the asset and 1 represents owning the asset, and $\bar{x}_{k}$ and $s_{k}$ are the sample mean and standard deviation (SD) of asset $k$ for all households).
The association between the PCA- and PAF-based proxy wealth indices was estimated by the Spearman's rank correlation coefficient (Appendix). Based on the overall small sample size of our study, we chose to divide each index into quartiles, rather than the standard quintiles or tertiles, representing: (i) most poor (MP), (ii) below average (BA), (iii) above average (AA), and (iv) most wealthy (MW) households.

\section{Proxy wealth indices and self-reported income and savings}

Corresponding wealth quartiles were also generated based on annual household per-capita income and on a combination of household income and savings, as follows: (i) high income ( $\geq 4000 \mathrm{CNY}$ per person per year) with savings, (ii) high income without savings, (iii) low income (< $4000 \mathrm{CNY}$ per person per year) with savings, and (iv) low income without savings. Households' categorical position for each respective index was assessed by a Kappa agreement, using the following cut-offs: 0 , no agreement; 0.01-0.2, poor agreement; 0.21-0.4, fair agreement; 0.41-0.6, moderate agreement; 0.61-0.8, substantial agreement; 0.81-1, almost perfect agreement [20]. Households that were re-ranked into different quartiles were examined in further detail. Mean scores per category were examined by means of Kruskal-Wallis (Appendix) analyses and a ratio of MW to MP was 
calculated. This entire process was then repeated for the pooled data from both villages $\left(m_{\text {total }}=504\right)$.

\section{Results}

Study compliance and operational results

From a total of 646 households in both villages, 504 (78.0\%) had complete datasets. This corresponded to $258 / 294$ (87.8\%) in the rural setting and 246/352 (69.9\%) in the peri-urban setting. Demographic variables are summarized in Table 1.

Comparison of income, savings, and possession of assets Table 2 shows annual household per-capita income and per-adult income, the primary source of income and the ability to save based on the primary source of income, for both settings. Annual household per-capita income was significantly associated with village setting $\left(\chi^{2}\right.$ test $\mathrm{p}<0.001)$, as was annual household per-adult income $\left(\chi^{2}\right.$ test $\left.\mathrm{p}<0.001\right)$. The primary source of household income was also associated with village setting $\left(\chi^{2}\right.$ test $\mathrm{p}$ $<0.001)$. Overall, $156(31.0 \%)$ households reported the ability to save money; however this was more frequent in the rural setting (106 or $41.1 \% v s$. peri-urban: 50 or $20.3 \% ; \chi^{2}$ test $\left.\mathrm{p}<0.001\right)$. Within both villages, saving was positively associated with annual household percapita income $\left(\chi^{2}\right.$ test $\mathrm{p}<0.001$ and $\chi^{2}$ test $\left.\mathrm{p}<0.001\right)$ and varied significantly according to primary source of income $\left(\chi^{2}\right.$ test $\mathrm{p}=0.040$ and $\chi^{2}$ test $\left.\mathrm{p}=0.027\right)$ for Wuyi and Laogang, respectively. In Wuyi, younger household heads were more likely to save than their older counterparts $\left(\chi^{2}\right.$ test $\left.\mathrm{p}=0.006\right)$, while there was no significant difference in Laogang. Within both settings, the amount of money saved per capita was also positively associated with annual household per-capita income $\left(\chi^{2}\right.$ test $\mathrm{p}<0.001$ and $\chi^{2}$ test $\left.\mathrm{p}=0.001\right)$, but not with the primary source of household income or with age for rural and peri-urban settings.

Table 3 shows the complete list of household durable assets, housing characteristics and utility and sanitation variables for both settings. Item ownership varied between and within villages. For example, all 246 periurban households but only 5 (1.9\%) rural households had tap water in the house. While 229 (88.8\%) rural households owned animals, the respective number and percentage was 46 (18.7\%) among peri-urban households.

Table 4 summarizes all significant associations between annual per-capita household income and ownership of household durable assets across pooled

Table 2 Self-reported annual household income and savings in rural (Wuyi village) and peri-urban (Laogang village) settings of Hunan province, China

\begin{tabular}{|c|c|c|c|c|}
\hline Income and savings & $\begin{array}{c}\text { Rural } \\
(\mathrm{n}=258)(\%)\end{array}$ & $\begin{array}{c}\text { Peri-urban } \\
(n=246)(\%)\end{array}$ & $\chi^{2}$ & p-value \\
\hline \multicolumn{5}{|c|}{ Annual household per-capita income (CNY) * } \\
\hline$<1000$ & $24(9.3)$ & $4(1.6)$ & 14.1 & $<0.001$ \\
\hline 1000-1999 & $55(21.3)$ & $26(10.6)$ & 10.8 & 0.001 \\
\hline 2000-3499 & $19(7.4)$ & $52(21.1)$ & 19.7 & $<0.001$ \\
\hline $3500-4999$ & $66(25.6)$ & $65(26.4)$ & 0.0 & 0.830 \\
\hline $5000-6999$ & $37(14.3)$ & $46(18.7)$ & 2.1 & 0.147 \\
\hline $7000-8999$ & $40(15.5)$ & $47(19.1)$ & 0.9 & 0.341 \\
\hline$\geq 9000$ & $17(6.6)$ & $6(2.5)$ & 3.6 & 0.058 \\
\hline \multicolumn{5}{|l|}{ Primary source of household income } \\
\hline Farming & $33(12.8)$ & $33(13.4)$ & 0.0 & 0.836 \\
\hline Fishing & $149(57.7)$ & $8(3.3)$ & 11.7 & $<0.001$ \\
\hline Farming and fishing & $38(14.7)$ & 0 & 39.2 & $<0.001$ \\
\hline Vegetable crops/animal rearing & $10(3.9)$ & $3(1.2)$ & 3.5 & 0.060 \\
\hline Small business & $8(3.1)$ & $27(11.0)$ & 12.0 & 0.001 \\
\hline Other & $20(7.8)$ & $175(71.1)$ & 12.1 & $<0.001$ \\
\hline \multicolumn{5}{|l|}{ Ability to save } \\
\hline Overall & $106(41.1)$ & $50(20.3)$ & 28.5 & $<0.001$ \\
\hline Farmers & $16(48.5)$ & $5(15.2)$ & 3.5 & 0.059 \\
\hline Fishermen & $50(33.6)$ & $1(12.5)$ & n.a. & n.a. \\
\hline Farmers and fishermen & $21(55.3)$ & 0 & n.a. & n.a. \\
\hline Animal rearers & $5(71.4)$ & 0 & n.a. & n.a. \\
\hline Businessmen & $6(75.0)$ & $12(44.4)$ & 3.4 & 0.061 \\
\hline Other & $8(40.0)$ & $32(18.3)$ & 14.0 & $<0.001$ \\
\hline
\end{tabular}

n.a., not applicable; ${ }^{*}$ Exchange rate CNY $1 \approx$ US\$ 0.16 at the time of survey (November/December 2006). 
Table 3 Prevalence of ownership of household durable assets, housing characteristics and utility and sanitation variables in rural (Wuyi village) and peri-urban (Laogang village) settings of Hunan province, China

\begin{tabular}{|c|c|c|c|c|}
\hline Variable & Rural $(n=258)$ & Peri-urban $(n=246)$ & $\chi^{2}$ & p-value \\
\hline \multicolumn{5}{|l|}{ Household durable assets } \\
\hline 1 Own house & $236(91.5)$ & $209(85.0)$ & 9.5 & 0.002 \\
\hline 2 Own land & $216(83.7)$ & $55(22.4)$ & 212.9 & $<0.001$ \\
\hline 3 Own animals & $229(88.8)$ & $46(18.7)$ & 253.5 & $<0.001$ \\
\hline 4 Gas rice cooker & $134(51.9)$ & $241(98.0)$ & 139.1 & $<0.001$ \\
\hline 5 Microwave & $215(83.3)$ & $227(92.3)$ & 8.8 & 0.003 \\
\hline 6 Black/white TV & $22(8.5)$ & $10(4.1)$ & 4.4 & 0.037 \\
\hline 7 Color TV & $236(91.5)$ & $228(92.7)$ & 0.1 & 0.720 \\
\hline $8 \mathrm{VCR}$ & $136(52.7)$ & $101(41.6)$ & 6.5 & 0.011 \\
\hline 9 Satellite dish & $82(31.8)$ & $6(2.4)$ & 75.7 & $<0.001$ \\
\hline 10 Phone line & $134(51.9)$ & $157(63.8)$ & 7.1 & 0.008 \\
\hline 11 Mobile phone & $82(31.8)$ & $142(57.7)$ & 33.9 & $<0.001$ \\
\hline 12 Bicycle & $161(62.4)$ & $18(7.3)$ & 167.9 & $<0.001$ \\
\hline 13 Motorbike & $81(31.4)$ & $18(7.3)$ & 46.6 & $<0.001$ \\
\hline 14 Electric fan & $246(95.3)$ & $238(96.7)$ & 0.2 & 0.694 \\
\hline 15 Air conditioner & $9(3.5)$ & $62(25.2)$ & 48.8 & $<0.001$ \\
\hline 16 Fridge & $50(19.4)$ & $138(56.1)$ & 72.1 & $<0.001$ \\
\hline 17 Washing machine & $124(48.1)$ & $172(69.9)$ & 23.9 & $<0.001$ \\
\hline 18 Simple tractor & $4(1.6)$ & $1(0.4)$ & 1.7 & 0.194 \\
\hline 19 Expensive tractor & $8(3.1)$ & $1(0.4)$ & 6.3 & 0.022 \\
\hline 20 Truck & $1(0.4)$ & $2(0.8)$ & 0.4 & 0.537 \\
\hline 21 Boat & $106(41.1)$ & $24(9.8)$ & 65.6 & $<0.001$ \\
\hline $22 \mathrm{Car}$ & $1(0.4)$ & $7(2.8)$ & 4.8 & 0.028 \\
\hline \multicolumn{5}{|l|}{ Housing characteristics } \\
\hline 23 Weak brick walls & $233(90.3)$ & $134(54.5)$ & 81.7 & $<0.001$ \\
\hline 24 Strong brick walls & $1(0.4)$ & $112(45.5)$ & 147.5 & $<0.001$ \\
\hline 25 Wooden walls & $22(8.5)$ & 0 & 21.9 & $<0.001$ \\
\hline 26 Weak brick roof & $169(65.5)$ & $40(16.3)$ & 125.8 & $<0.001$ \\
\hline 27 Strong brick roof & $86(33.3)$ & $206(83.7)$ & 131.3 & $<0.001$ \\
\hline 28 Wooden roof & $1(0.4)$ & 0 & 1.0 & 0.328 \\
\hline 29 Mud floor & $28(10.9)$ & $3(1.2)$ & 20.2 & $<0.001$ \\
\hline 30 Cement floor & $155(60.1)$ & $68(27.6)$ & 53.7 & $<0.001$ \\
\hline 31 Porcelain floor & $57(22.1)$ & $174(70.7)$ & 120.0 & $<0.001$ \\
\hline 32 Wooden floor & $16(6.2)$ & $1(0.4)$ & 13.0 & $<0.001$ \\
\hline \multicolumn{5}{|l|}{ Utility and sanitation } \\
\hline 33 Tap water & $5(1.9)$ & $246(100.0)$ & 483.4 & $<0.001$ \\
\hline 34 Hand pump water & $254(98.4)$ & $1(0.4)$ & 487.2 & $<0.001$ \\
\hline 35 Flushable toilet & $96(37.2)$ & $215(87.4)$ & 133.4 & $<0.001$ \\
\hline 36 Medicine at home & $12(4.7)$ & 95 (38.6) & 86.6 & $<0.001$ \\
\hline 37 Soap & $256(99.2)$ & $242(98.4)$ & 1.1 & 0.293 \\
\hline 38 Over-crowding & $32(12.4)$ & $16(6.5)$ & 5.1 & 0.024 \\
\hline
\end{tabular}

data from both rural and peri-urban settings, with the model accounting for $48.6 \%$ of variation in the data.

\section{Comparison of asset-based indices constructed using PCA and PAF}

Examination of the initial correlation matrix for both settings identified inter-item $\phi$ correlations $>0.8$, excluding numerous variables from further analyses. The final correlation matrix consisted of 15 variables for Wuyi and 11 variables for Laogang, and 14 variables for the pooled data (Table 5).

Bartlett's test of sphericity was significant in both settings (rural: $\chi^{2}$ test $\mathrm{p}<0.001$ and peri-urban: $\chi^{2}$ test $\mathrm{p}$ $<0.001)$ and for the pooled data $\left(\chi^{2}\right.$ test $\left.\mathrm{p}<0.001\right)$, and the respective KMO statistics were $0.788,0.726$ and 
Table 4 Significant associations between annual per-capita household income and ownership of household durable assets, as assessed by a stepwise multinomial logistic regression analysis.

\begin{tabular}{|c|c|c|c|c|c|c|c|c|c|c|c|c|c|c|}
\hline \multirow[t]{3}{*}{ Variable } & \multicolumn{14}{|c|}{ Annual household per-capita income $(\mathrm{CNY}) *(n=504)$} \\
\hline & \multicolumn{2}{|c|}{$<1000$} & \multicolumn{2}{|c|}{ 1000-1999 } & \multicolumn{2}{|c|}{$2000-3499$} & \multicolumn{2}{|c|}{$3500-4999$} & \multicolumn{2}{|c|}{$5000-6999$} & \multicolumn{2}{|c|}{$7000-8999$} & \multicolumn{2}{|c|}{$>9000$} \\
\hline & $\begin{array}{c}\text { OR } \\
(95 \% \mathrm{Cl})\end{array}$ & p-value & $\begin{array}{c}\text { OR } \\
(95 \% \mathrm{Cl})\end{array}$ & p-value & $\begin{array}{c}\text { OR } \\
(95 \% \mathrm{Cl})\end{array}$ & p-value & $\begin{array}{c}\text { OR } \\
(95 \% \mathrm{Cl})\end{array}$ & p-value & $\begin{array}{c}\text { OR } \\
(95 \% \mathrm{Cl})\end{array}$ & p-value & $\begin{array}{c}\text { OR } \\
(95 \% \mathrm{Cl})\end{array}$ & p-value & $\begin{array}{c}\text { OR } \\
(95 \% \mathrm{Cl})\end{array}$ & p-value \\
\hline 4 Gas rice cooker & $\begin{array}{c}2.1 \\
(0.4-4.2)\end{array}$ & 0.120 & $\begin{array}{c}2.2 \\
(0.4-5.4)\end{array}$ & 0.115 & $\begin{array}{c}2.0 \\
(0.2-4.8)\end{array}$ & 0.121 & $\begin{array}{c}2.2 \\
(0.6-7.1)\end{array}$ & 0.115 & $\begin{array}{c}4.4 \\
(2.0-6.1)\end{array}$ & 0.037 & $\begin{array}{c}2.9 \\
(0.8-3.8)\end{array}$ & 0.110 & $\begin{array}{c}3.0 \\
(0.6-5.1)\end{array}$ & 0.111 \\
\hline 7 Color TV & $\begin{array}{c}2.8 \\
(0.4-6.7)\end{array}$ & 0.087 & $\begin{array}{c}3.8 \\
(2.1-5.6)\end{array}$ & 0.049 & $\begin{array}{c}8.5 \\
(6.7-12.0)\end{array}$ & 0.004 & $\begin{array}{c}2.9 \\
(0.8-4.0)\end{array}$ & 0.087 & $\begin{array}{c}4.9 \\
(2.8-6.3)\end{array}$ & 0.027 & $\begin{array}{c}3.1 \\
(0.9-4.9)\end{array}$ & 0.053 & $\begin{array}{c}3.6 \\
(1.8-4.5)\end{array}$ & 0.050 \\
\hline $8 \mathrm{VCR}$ & $\begin{array}{c}2.2 \\
(0.4-3.7)\end{array}$ & 0.115 & $\begin{array}{c}1.0 \\
(0.5-5.2)\end{array}$ & 0.180 & $\begin{array}{c}0.6 \\
(0.1-2.5)\end{array}$ & 1.240 & $\begin{array}{c}0.6 \\
(0.1-2.1)\end{array}$ & 1.240 & $\begin{array}{c}2.5 \\
(0.7-4.3)\end{array}$ & 0.113 & $\begin{array}{c}3.6 \\
(1.0-7.7)\end{array}$ & 0.051 & $\begin{array}{c}4.0 \\
(1.5-5.8)\end{array}$ & 0.047 \\
\hline 9 Satellite dish & $\begin{array}{c}4.4 \\
(3.0-6.1)\end{array}$ & 0.037 & $\begin{array}{c}4.3 \\
(2.9-6.6)\end{array}$ & 0.039 & $\begin{array}{c}4.9 \\
(3.1-6.0)\end{array}$ & 0.028 & $\begin{array}{c}4.0 \\
(2.2-7.1)\end{array}$ & 0.050 & $\begin{array}{c}4.3 \\
(2.5-7.4)\end{array}$ & 0.039 & $\begin{array}{c}4.4 \\
(2.1-6.8)\end{array}$ & 0.038 & $\begin{array}{c}4.8 \\
(2.1-7.6)\end{array}$ & 0.028 \\
\hline 11 Mobile phone & $\begin{array}{c}4.1 \\
(3.2-5.6)\end{array}$ & 0.044 & $\begin{array}{c}4.0 \\
(3.1-6.2)\end{array}$ & 0.047 & $\begin{array}{c}7.3 \\
(4.3-12.9)\end{array}$ & 0.007 & $\begin{array}{c}3.5 \\
(3.2-5.3)\end{array}$ & 0.061 & $\begin{array}{c}7.4 \\
(4.0-9.8)\end{array}$ & 0.006 & $\begin{array}{c}3.2 \\
(2.2-6.8)\end{array}$ & 0.048 & $\begin{array}{c}3.5 \\
(2.5-6.9)\end{array}$ & 0.060 \\
\hline 12 Bicycle & $\begin{array}{c}6.2 \\
(3.3-9.6)\end{array}$ & 0.012 & $\begin{array}{c}6.4 \\
(4.2-8.7)\end{array}$ & 0.011 & $\begin{array}{c}6.2 \\
(4.6-9.8)\end{array}$ & 0.012 & $\begin{array}{c}8.5 \\
(5.5-12.1)\end{array}$ & 0.004 & $\begin{array}{c}7.3 \\
(4.1-12.2)\end{array}$ & 0.007 & $\begin{array}{c}3.3 \\
(0.9-5.7)\end{array}$ & 0.069 & $\begin{array}{c}2.9 \\
(0.6-3.1)\end{array}$ & 0.110 \\
\hline 14 Electric fan & $\begin{array}{c}3.0 \\
(0.6-5.7)\end{array}$ & 0.110 & $\begin{array}{c}2.9 \\
(0.4-4.8)\end{array}$ & 0.110 & $\begin{array}{c}4.5 \\
(3.9-8.1)\end{array}$ & 0.034 & $\begin{array}{c}2.8 \\
(0.6-3.1)\end{array}$ & 0.111 & $\begin{array}{c}4.0 \\
(1.4-7.3)\end{array}$ & 0.047 & $\begin{array}{c}4.6 \\
(2.0-7.1)\end{array}$ & 0.030 & $\begin{array}{c}4.2 \\
(3.3-7.2)\end{array}$ & 0.041 \\
\hline 15 Air conditioner & $\begin{array}{c}0.1 \\
(0.2-3.6)\end{array}$ & 0.839 & $\begin{array}{c}0.3 \\
(0.0-1.4)\end{array}$ & 0.550 & $\begin{array}{c}2.3 \\
(0.6-4.7)\end{array}$ & 0.129 & $\begin{array}{c}4.6 \\
(2.8-7.6)\end{array}$ & 0.033 & $\begin{array}{c}4.2 \\
(3.3-6.9)\end{array}$ & 0.040 & $\begin{array}{c}3.9 \\
(1.5-6.3)\end{array}$ & 0.049 & $\begin{array}{c}2.7 \\
(2.0-4.0)\end{array}$ & 0.112 \\
\hline 17 Washing machine & $\begin{array}{c}1.4 \\
(0.2-2.3)\end{array}$ & 0.245 & $\begin{array}{c}2.9 \\
(0.3-3.3)\end{array}$ & 0.110 & $\begin{array}{c}2.0 \\
(0.8-4.4)\end{array}$ & 0.121 & $\begin{array}{c}3.1 \\
(1.2-5.6)\end{array}$ & 0.045 & $\begin{array}{c}1.4 \\
(0.3-2.2)\end{array}$ & 0.245 & $\begin{array}{c}1.6 \\
(0.0-2.6)\end{array}$ & 0.204 & $\begin{array}{c}0.3 \\
(1.2-4.9)\end{array}$ & 0.550 \\
\hline
\end{tabular}

Adjusted odds ratios (OR) including 95\% confidence intervals (Cl) shown for pooled data from both rural (Wuyi village) and peri-urban (Laogang village) settings of Hunan province, China The model accounts for $48.6 \%$ of variation in the data; ${ }^{*}$ Exchange rate CNY $1 \approx$ US\$ 0.16 at the time of survey (November/December 2006). 
Table 5 Principal components (PCs) or principal factors (PFs) extracted by principal components analysis (PCA) and principal axis factoring (PAF), showing component or factor loadings.

\begin{tabular}{|c|c|c|c|c|c|c|c|}
\hline \multirow{2}{*}{$\begin{array}{l}\text { Variable } \\
\text { (\% variance accounted for) }\end{array}$} & \multicolumn{4}{|c|}{ Rural (Wuyi) } & \multicolumn{3}{|c|}{ Peri-urban (Laogang) } \\
\hline & $\begin{array}{c}\text { PC 1, PF } 1 \\
(24.3 \%)\end{array}$ & $\begin{array}{c}\text { PC 2, PF } 2 \\
(11.0 \%)\end{array}$ & $\begin{array}{c}\text { PC 3, PF } 3 \\
(9.4 \%)\end{array}$ & $\begin{array}{c}\text { PC 4, PF } 4 \\
(8.9 \%)\end{array}$ & $\begin{array}{c}\text { PC 1, PF } 1 \\
(27.8 \%)\end{array}$ & $\begin{array}{c}\text { PC 2, PF } 2 \\
(16.5 \%)\end{array}$ & $\begin{array}{c}\text { PC 3, PF } 3 \\
(12.7 \%) \\
\end{array}$ \\
\hline 2 Own land & & & - 0.421, n.a. & $\mathbf{0 . 5 6 4}, 0.436$ & & $0.574,-0.408$ & \\
\hline 3 Own animals & & & - 0.469, n.a. & 0.493 , п.а. & n.a. & n.a. & n.a. \\
\hline 4 Gas rice cooker & $0.638,0.573$ & & & & n.a. & n.a. & n.a. \\
\hline 5 Microwave & $0.464,0.388$ & & & & n.a. & n.a. & n.a. \\
\hline $8 \mathrm{VCR}$ & $\mathbf{0 . 4 6 5}, 0.405$ & 0.444, n.a. & & & $0.702,0.613$ & & \\
\hline 9 Satellite dish & $0.527,0.483$ & & & & n.a. & n.a. & n.a. \\
\hline 10 Phone line & n.a. & n.a. & n.a. & n.a. & & $-0.736,0.527$ & \\
\hline 11 Mobile phone & $0.611,0.553$ & & & & $0.668,0.585$ & & \\
\hline 13 Motorbike & $0.595,0.525$ & & & & n.a. & n.a. & n.a. \\
\hline 15 Air conditioner & n.a. & n.a. & n.a. & n.a. & $0.585,0.500$ & & \\
\hline 16 Fridge & $0.444,0.373$ & & & & $0.661,0.614$ & & \\
\hline 17 Washing machine & $\mathbf{0 . 5 8 0}, 0.533$ & 0.430, n.a. & & & $0.734,0.668$ & & \\
\hline 21 Boat & & & & $0.669,0.429$ & & & \\
\hline 27 Weak brick roof & $-0.564,-0.554$ & & & & n.a. & n.a. & n.a. \\
\hline 28 Strong brick roof & n.a. & n.a. & n.a. & n.a. & & $0.827,0.849$ & \\
\hline 31 Porcelain floor & $0.605, \mathbf{0 . 6 0 1}$ & n.a., -0.482 & & & $0.650, \mathbf{0 . 6 4 7}$ & & n.a., -0.500 \\
\hline 35 Flushable toilet & $0.694,0.676$ & & & & $0.561,0.512$ & & \\
\hline 36 Medicines at home & n.a. & n.a. & n.a. & n.a. & & & $0.677,0.433$ \\
\hline 38 Over-crowding & & & $0.678,0.453$ & & n.a. & n.a. & n.a. \\
\hline
\end{tabular}

Values shown are for rural (Wuyi village) (left) and peri-urban (Laogang village) (right) settings, Hunan province, China*

n.a, not applicable; ${ }^{1}$ Factor loadings reported only if they exceed the cut-off eigenvector of $|0.3| ;{ }^{*}$ Rotation method: no rotation used to maximize the squared loadings of the columns.

NB Indices were created using only the first component or factor. Remaining components or factors are shown for clarification purposes. Where variables loaded on more than one component or factor, the one selected is shown in bold. This was done based on the co-efficient $\alpha$ score.

0.863 . The anti-image correlation matrix measures of sampling adequacy were above 0.636 and the off-diagonal values were below $|0.345|$ for each setting and pooled data. Cronbach's coefficient $\alpha$ for the 15-item scale was 0.652 in Wuyi, 0.615 for the 11 -item scale in Laogang, and 0.667 for the 14-item scale pooled data.

PCA and PAF revealed four components or factors with eigenvalues $>1.0$ in the rural setting and three in the peri-urban setting. In each case the first component or factor comprised of several heavily loaded variables (eigenvectors $>0.3$ ) and accounted for $24.3 \%$ and $27.8 \%$ of the variation in the data from Wuyi and Laogang, respectively, while the remaining components or factors had fewer variables and explained a smaller proportion of the variation (Table 5). For the pooled data, three components or factors had eigenvalues $>1.0$ and the first component or factor accounted for $33.9 \%$ of the variation in the data. The un-rotated extraction method was selected for PCA and PAF in both settings and for the pooled data, as rotation did not add measurably to the simplicity or fit of each of the models. The relative magnitude and direction of the weights in the PCA and PAF models are consistent within settings (Table 5) and across pooled data (data not shown).

For both settings, standardized indices of relative wealth were created using heavily loaded variables of the first PC, or the first PF, with variables weighted according to their eigenvector, as in the equation. All four indices showed evidence of clumping and truncation (Figure 1). The PCA and PAF indices correlated well with each other within each village (for both settings Spearman's rho $=0.99, \mathrm{p}<0.001)$. The Kappa agreement was found to be almost perfect, with values of 0.91 and 0.81 for Wuyi and Laogang, respectively. In Wuyi, 17 (6.6\%) households were in different quartiles according to factor extraction method, while this was the case for 35 (14.2\%) households in Laogang (Figure 2).

\section{Comparison of proxy wealth indices with self-reported income and savings}

Both PCA and PAF indices showed a weak, but significant, positive correlation with annual household percapita income (Spearman's rho $=0.27, \mathrm{p}<0.001$ for PCA and Spearman's rho $=0.26, \mathrm{p}<0.001$ for PAF), with annual household per-adult income (Spearman's 


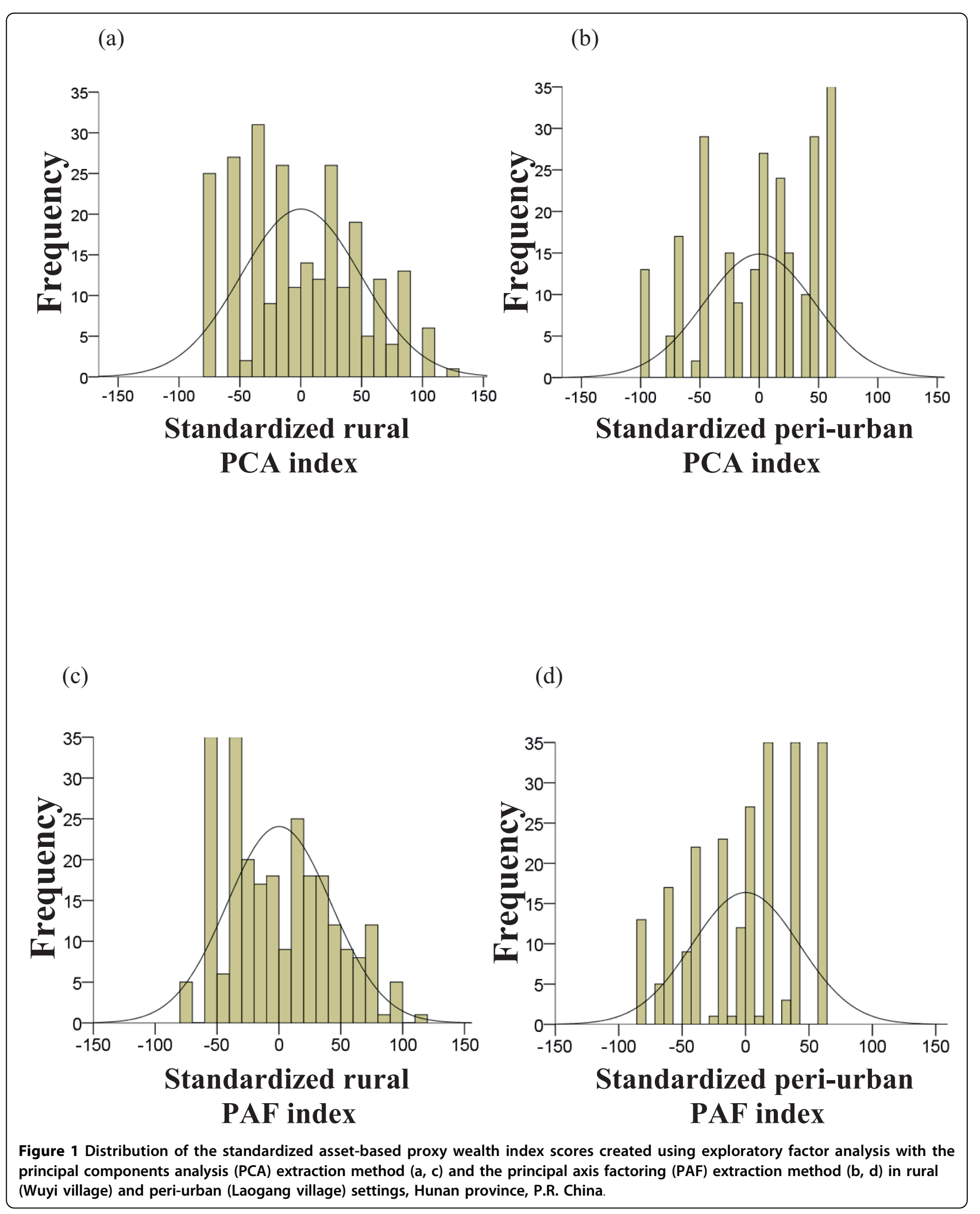


(a)

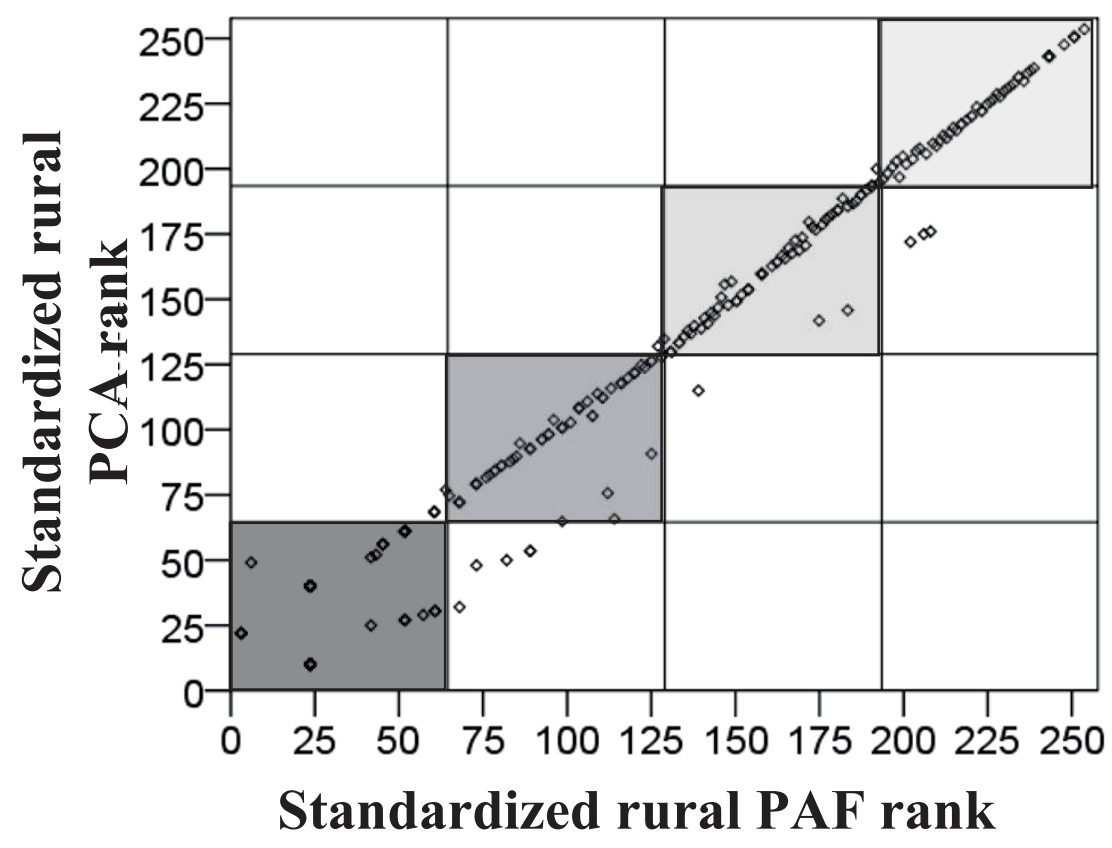

(b)

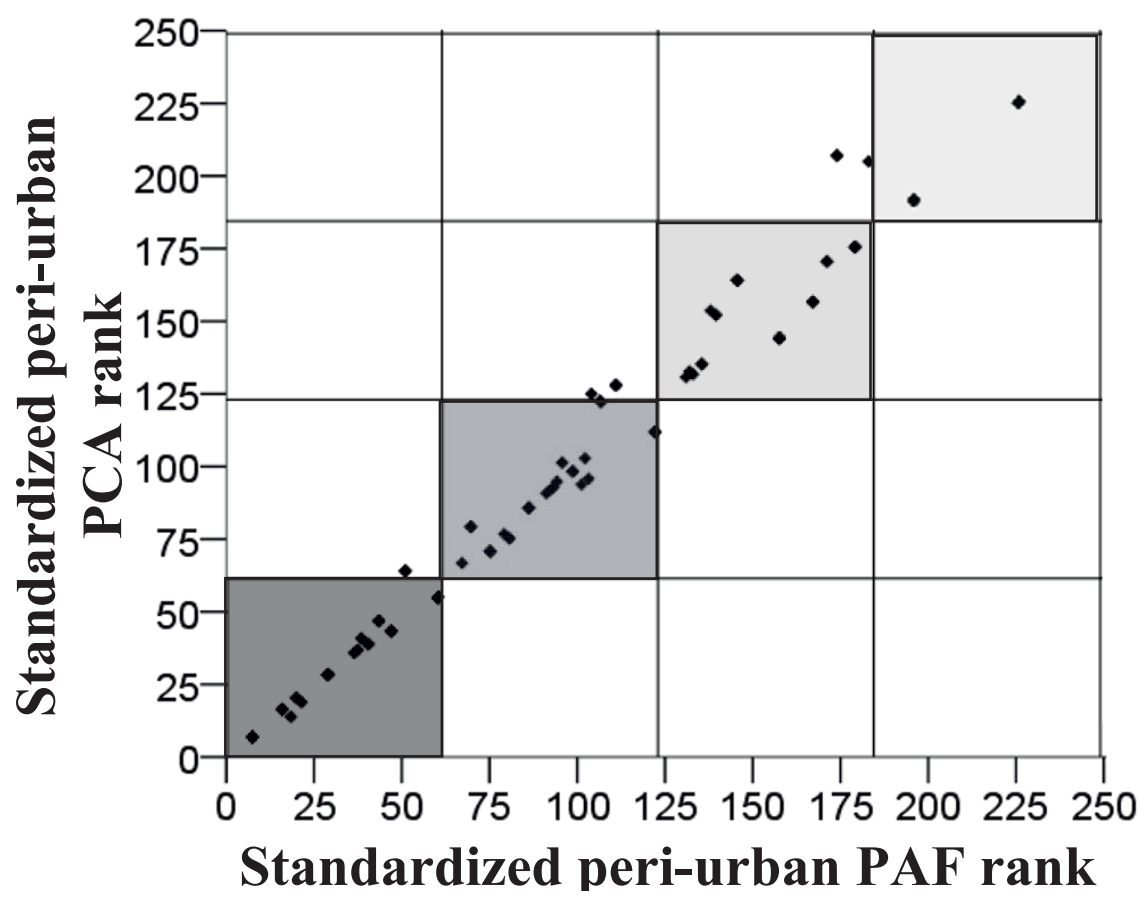

Figure 2 Correlation of the standardized asset-based proxy wealth index scores created using exploratory factor analysis with the principal components analysis (PCA) and the principal axis factoring (PAF) extraction methods in (a) rural (Wuyi village) and (b) periurban (Laogang village) settings of Hunan province, P.R. China. Lines vertical to the axes define the respective wealth quartiles of each index for rural (dashed) and peri-urban (dotted) settings, respectively. 
rho $=0.30, \mathrm{p}<0.001$ for PCA and Spearman's rho $=$ $0.29, \mathrm{p}<0.001$ for PAF) and with annual household percapita savings (Spearman's rho $=0.16, p=0.016$ for PCA and Spearman's rho $=0.16, p=0.017$ for PAF) in the rural setting. Similarly, in the peri-urban setting both indices were weakly, but significantly, correlated with annual household income (per-capita income Spearman's rho $=0.27, \mathrm{p}<0.001$ for PCA and Spearman's rho $=0.28, \mathrm{p}<0.001$ for PAF and per-adult income Spearman's rho $=0.36, \mathrm{p}<0.001$ for PCA and Spearman's rho $=0.37, \mathrm{p}<0.001$ for PAF) and with annual household per-capita savings (Spearman's rho = $0.26, p=<0.001$ for PCA and Spearman's rho $=0.27$, $\mathrm{p}<0.001$ for PAF). Mean asset-based index scores, derived either by PCA or PAF, were significantly different between combined income and savings categories in both settings (PCA rural score (i) high income with savings: 21.5, (ii) high income without savings: 12.8, (iii) low income with savings: -8.0 , and (iv) low income without savings: -16.3; PCA peri-urban score (i) high income with savings: 25.4 , (ii) high income without savings: 11.5, (iii) low income with savings: 2.6 , and (iv) low income without savings: -16.8 ; Kruskal-Wallis $=27.6$, degrees of freedom (d.f.) $=3, \mathrm{p}<0.001$ for the rural setting and Kruskal-Wallis $=32.0$, d.f. $=3, \mathrm{p}<0.001$ for the peri-urban setting) (Figure 3).

We found wide disparities among the asset-based proxy wealth quartiles in mean annual household percapita income and per-adult income. To illustrate this issue, using the PCA extraction method, we found highly significant Kruskal-Wallis test results both for rural and peri-urban settings (annual household percapita income in rural setting Kruskal-Wallis $=14.7$, d.f. $=3, \mathrm{p}=0.002$ and peri-urban setting Kruskal-Wallis = 21.0, d.f. $=3, \mathrm{p}<0.001$ and for per-adult income in rural setting Kruskal-Wallis $=23.7$, d.f. $=3, p=0.001$ and peri-urban setting Kruskal-Wallis $=35.1$, d.f. $=3$, $\mathrm{p}<0.001)$. Similarly, we found disparities among wealth quartiles in a household's ability to save for both settings $\left(\chi^{2}\right.$ test $\mathrm{p}=0.014$ and $\chi^{2}$ test $\mathrm{p}<0.001$ for rural and peri-urban settings, respectively) (Table 6, rural setting only). This pattern was also confirmed when comparing mean annual household per-capita savings among wealth quartiles for the peri-urban setting (Kruskal-Wallis $=17.3$, d.f. $=3, \mathrm{p}<0.001$ ) but not for the rural setting (Kruskal-Wallis $=6.9$, d.f. $=3, \mathrm{p}=0.077$ ) . Disparities in a combination of annual household income and saving were also apparent between MW

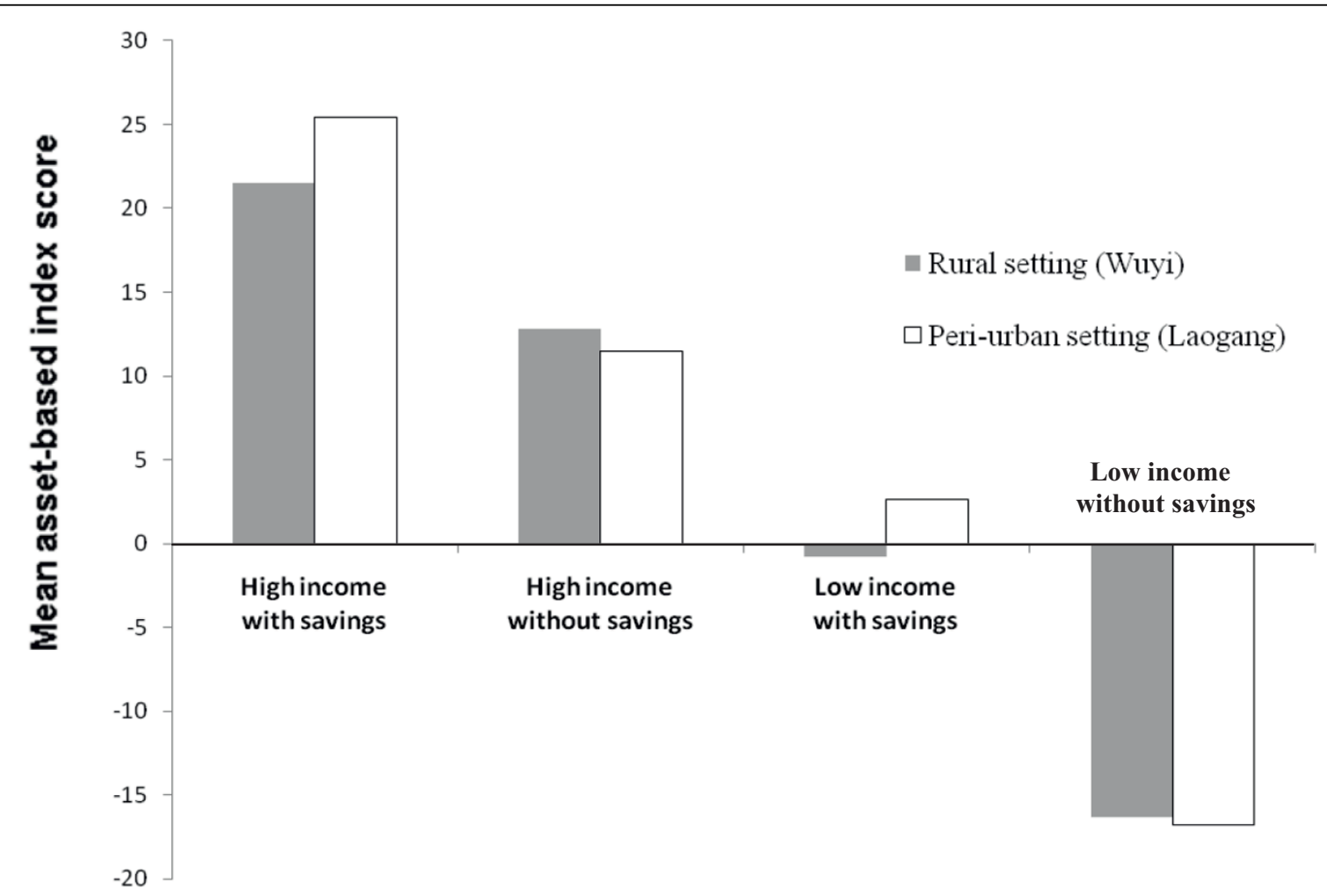

Figure 3 Mean asset-based index scores, derived either by principal components analysis (PCA), according to income and savings categories. Values shown are for rural (Wuyi village) (filled) and peri-urban (Laogang village) (blank) settings, Hunan province, P.R. China. 
Table 6 The relationship between the proxy wealth index generated using principal components analysis (PCA) and income and savings, among households in a rural (Wuyi village) setting, Hunan province, China

\begin{tabular}{|c|c|c|c|c|c|c|c|}
\hline \multirow[t]{2}{*}{ Variable } & \multicolumn{4}{|c|}{ Wealth quartile* } & \multirow[b]{2}{*}{ MW:MP** } & \multirow[b]{2}{*}{$\chi^{2}$} & \multirow[b]{2}{*}{ p-value } \\
\hline & $\begin{array}{l}\text { Most poor } \\
(\mathrm{n}=64)\end{array}$ & $\begin{array}{c}\text { Below average } \\
\quad(n=66)\end{array}$ & $\begin{array}{l}\text { Above average } \\
\quad(n=64)\end{array}$ & $\begin{array}{l}\text { Most wealthy } \\
(\mathrm{n}=64)\end{array}$ & & & \\
\hline Ability to save money & $15(23.4 \%)$ & $23(34.8 \%)$ & $29(45.3 \%)$ & $39(60.9 \%)$ & 2.6 & 10.6 & 0.014 \\
\hline Low income without savings & $34(53.1 \%)$ & $35(53.0 \%)$ & $20(31.3 \%)$ & $14(21.9 \%)$ & 0.4 & 19.6 & $<0.001$ \\
\hline Low income with savings & $5(7.8 \%)$ & $8(12.1 \%)$ & $6(9.4 \%)$ & $10(15.6 \%)$ & 2.0 & 1.9 & 0.588 \\
\hline High income without savings & $15(23.4 \%)$ & $12(18.2 \%)$ & $15(23.4 \%)$ & $11(17.2 \%)$ & 0.7 & 4.1 & 0.247 \\
\hline High income with savings & $10(15.6 \%)$ & $11(16.7 \%)$ & $23(35.9 \%)$ & $29(45.3 \%)$ & 2.9 & 20.1 & $<0.001$ \\
\hline
\end{tabular}

${ }^{*} \mathrm{n}=$ Number of households in each category; ${ }^{*}=$ Most wealthy to most poor ratio

and MP quartiles, in both settings (Table 6, rural setting only).

When the analyses were repeated for pooled data, we found that households from each setting were highly unequally distributed among the proxy wealth quartiles (Figure 4). Both PCA- and PAF-based indices showed weak, but significant, positive correlations with annual household per-capita income (Spearman's rho $=0.27$, $\mathrm{p}<0.001$ for PCA and Spearman's rho $=0.28, \mathrm{p}<0.001$ for PAF), per-adult income (Spearman's rho $=0.21$, $\mathrm{p}<0.001$ for PCA and Spearman's rho $=0.22, \mathrm{p}<0.001$ for PAF) and per-capita savings (Spearman's rho $=0.26$, $\mathrm{p}<0.001$ for PCA and Spearman's rho $=0.27, \mathrm{p}<0.001$ for PAF). Kappa agreements of the PCA and PAF indices with the index based on per-capita income were poor (0.12 and 0.13 , respectively). Wide disparities in household durable assets, housing characteristics, utilities and sanitation were clear among the four proxy wealth categories. Disparities in a combination of annual household income and saving were also apparent between MW and MP quartiles (Table 7).

\section{Discussion}

This study contributes methodologically and analytically to research into measurements of wealth and SEP in a country undergoing rapid social, economic, demographic and health transitions [21]. Using household-level data collected with a pre-tested and standardized questionnaire in a rural and a peri-urban setting in Hunan province, P.R. China, we examined asset-based proxy wealth measurements constructed by two common exploratory factor analysis approaches. Our results confirm that, although they have different underlying theoretical assumptions, both PCA and PAF are equally effective statistical techniques in evaluating relative wealth among households. Consistent with the proxy wealth indices derived in the Demographic and Health Surveys (DHS) [9], we selected the first un-rotated component/factor, which accounted for $24.3 \%$ (rural) and $27.8 \%$ (peri-urban) of the overall variation in the data. Proxy wealth index scores were significantly associated with wealth quartiles based on a household's selfreported annual income, and a combination of income and savings, but not savings alone. We found large discrepancies between MW and MP households within and between the two study villages. However, further analyses of pooled results suggest that when combining data from the two settings, these differences may be structural, owing more to urbanization, modernization and accessibility of goods and services, rather than wealth per se. This may be particularly true for P.R. China, which is undergoing a long-term, yet spatially heterogenous, period of industrialization and development [22-24].

Salaries in the rural setting were frequently at the low (e.g., $\mathrm{CNY}<2000$ ) and the high (e.g., $\mathrm{CNY}>7000$ ) ends of the spectrum, while those in the peri-urban setting seemed clustered in the middle. This is possibly explained by reporting bias, as many of the peri-urban respondents were the next of kin and not the household head, or, by unaccounted externalities (e.g., government policies) imposing a spatial correlation on household income [25]. As in most of rural P.R. China, household income was predominantly (in the case of 220 , or $85.3 \%$, households) sourced from fishing and/or farming activities [26]. However, in the peri-urban setting our questionnaire survey failed to capture the most common source of primary income $(175$, or $71.1 \%$, peri-urban household respondents reported 'other' primary source of income), although anecdotal evidence suggests that these are mainly remittances from non-resident household members and occasionally government payments or basic pension schemes. Saving was more commonly reported in the rural setting which, assuming no reporting bias, is likely a result of less secure employment, and hence greater income uncertainty [27], and a weakened social security system bringing about high user charges for public services [28]. We found that age was an important factor in saving patterns of rural households, implying that younger households smooth consumption, perhaps in order to invest so that their living standards can be enhanced in the future. Furthermore, stronger 
(a)

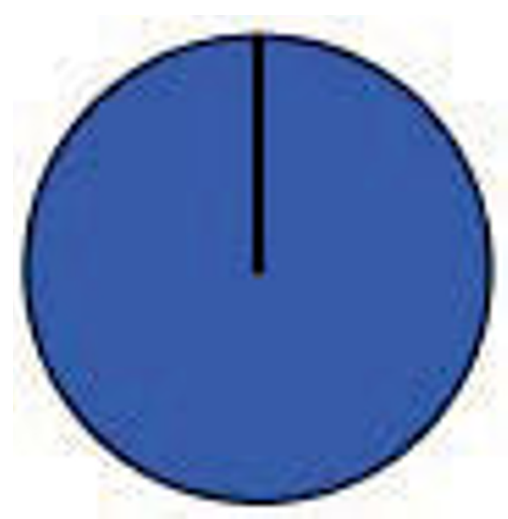

Most poor $(n=127)$

(c)

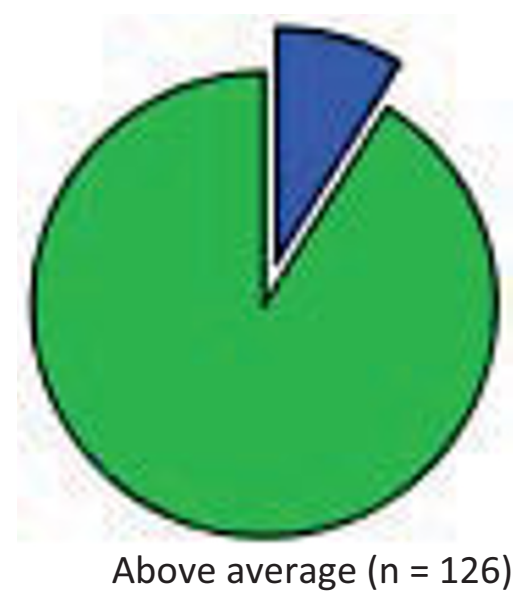

(b)

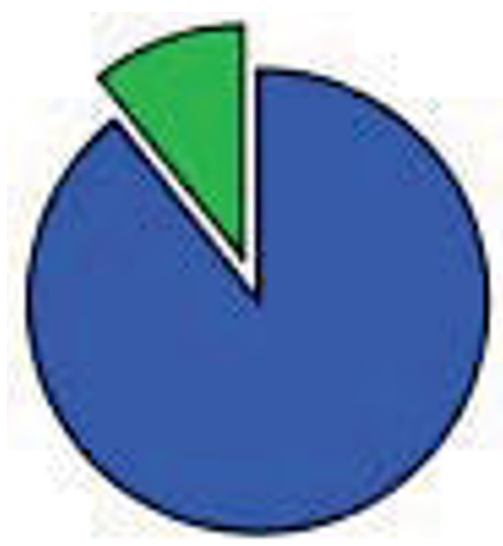

Below average $(n=126)$

(d)

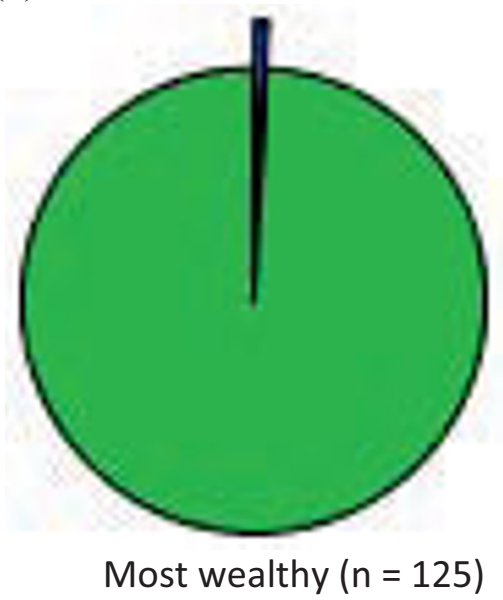

Figure 4 Proportion of households within each proxy wealth quartile that are in the rural (Wuyi village) (blue) and peri-urban (Laogang village) (green) settings of Hunan province, P.R. China, respectively. Quartiles represent (a) most poor ( $n=127)$; (b) below average $(n=126)$; $(c)$ above average $(n=126)$; and (d) most wealthy $(n=125)$ categories for pooled data from both villages.

Table 7 The relationship between the proxy wealth index generated using principal components analysis (PCA) and income and savings, among households in rural (Wuyi village) and peri-urban (Laogan village) settings, Hunan province, China

\begin{tabular}{|c|c|c|c|c|c|c|c|}
\hline \multirow[t]{2}{*}{ Variable } & \multicolumn{4}{|c|}{ Wealth quartile* } & \multirow[b]{2}{*}{ MW:MP** } & \multirow[b]{2}{*}{$\chi^{2}$} & \multirow[b]{2}{*}{ p-value } \\
\hline & $\begin{array}{l}\text { Most poor } \\
(n=127)\end{array}$ & $\begin{array}{l}\text { Below average } \\
(n=126)\end{array}$ & $\begin{array}{l}\text { Above average } \\
\quad(n=126)\end{array}$ & $\begin{array}{l}\text { Most wealthy } \\
\quad(n=125)\end{array}$ & & & \\
\hline Ability to save money & 43 (33.9\%) & $51(40.5 \%)$ & $29(23.0 \%)$ & $33(26.4 \%)$ & 0.8 & 15.2 & 0.002 \\
\hline Low income without savings & $59(46.4 \%)$ & $44(34.9 \%)$ & $66(52.4 \%)$ & $54(43.2 \%)$ & 0.9 & 10.8 & 0.013 \\
\hline Low income with savings & $19(15.0 \%)$ & $11(8.7 \%)$ & $9(7.1 \%)$ & $5(4.0 \%)$ & 0.3 & 15.2 & 0.002 \\
\hline High income without savings & $25(19.7 \%)$ & $31(24.6 \%)$ & $31(24.6 \%)$ & $38(30.4 \%)$ & 1.5 & 15.0 & 0.003 \\
\hline High income with savings & $24(18.9 \%)$ & $40(31.8 \%)$ & $20(15.9 \%)$ & $28(22.4 \%)$ & 1.2 & 11.1 & 0.011 \\
\hline
\end{tabular}

${ }^{*} \mathrm{n}=$ Number of households in each category; ${ }^{*}=$ Most wealthy to most poor ratio 
social networks in the rural setting may impact on decision making behavior such as household expenditure patterns, while costs of basic needs may also be substantially lower in rural areas $[29,30]$.

Though proxy measures of wealth are welcome tools in international health research [15], the construction of indices based on exploratory factor analysis has been criticized for being subjective and unstandardized [12,31]. Conversely, several studies have reported that the assetbased index is a more accurate indicator of long-term wealth than income and consumption data $[14,15]$. Nonetheless, the reliability of the asset-based index has also been questioned by some authors [11]. Indeed, using binary data, such as ownership of a particular asset, may violate underlying assumptions that the measured variables are related in a linear fashion to the underlying latent constructs (i.e., wealth). Our results confirm those in other settings [15,32], indicating internal consistency and robustness in both methods, particularly for higher ranking households. While household income showed a significant association with ownership of numerous household durable assets, the correlation between the asset-based proxy wealth indices and the direct measures of wealth was low. The proxy wealth models explained a higher proportion of data in the peri-urban setting than the rural setting $(27.8 \%$ vs. $24.3 \%$ for PCA), which may add strength to the concern that an asset-based index is a more 'appropriate' measure of wealth in urban areas compared with rural areas $[18,31]$. To increase these percentages, other data analysis tools such as the modified hierarchical ordered probit (HOPIT) model [33] and multiple correspondence analysis (MCA) [34] may be used to weight the indicators and should be explored further in subsequent studies.

Questions remain regarding the choice and number of variables to be included, although it has been suggested that the data should comprise of 10-15 subjects per variable [35]. With 15 and 11 variables in the rural and peri-urban villages, respectively, our sample size of 246258 households was satisfactory. Sampling adequacy was further confirmed by the KMO measure (KMO $>0.7$ is said to be 'meritious'), and by Bartlett's test of sphericity, which indicated that the correlation matrices were not identity matrices, and hence the factor model was appropriate. Retaining only components or factors with eigenvalues $>1.0$ ensured that they explained at least as much variance in the data as one measured variable, since the variance accounted for by each of the components is its associated eigenvalue. However, Cronbach's coefficient $\alpha$ was just below 0.7 for each setting, indicating that up to $50 \%$ of the variance in the items may be attributable to measurement error. Similar to other studies, we found that the first PC and the first PF only explained a low percentage of variation in the data
(20-30\%). This finding suggests that, while the derived indices do provide a proxy measure of wealth, it is estimated with a considerable level of inaccuracy $[31,32,36]$. Although inclusion of the remaining components or factors helps explain some of the remaining variation, it is unclear if, and how, this should be done [37].

Consistent with findings from other studies, both PCA and PAF showed signs of clumping and truncation, hindering their ability to accurately classify wealth quartile borderline households, although this was less obvious in the rural data $[18,32,34]$ (see Figure 1). Clumping may be a statistical phenomenon caused by a lack of input variables that can adequately distinguish between households of a similar economic status [18], or it may be a product of social and economic homogeneity stemming from half a century of socialist rule in P.R. China $[27,31]$. In the peri-urban setting, including ownership of computers and household Internet service may have helped further differentiate between the AA and MW. Differentiating between the age, price, condition and quantity of specific assets may reduce the effect of clumping and/or truncation and should be explored in greater detail, although results from previous studies imply that this information may not add to the accuracy or robustness of the index [14,38]. Furthermore, in our study the few households which were re-classified into different quartiles according to the factor extraction method employed only moved to immediately adjacent quartiles.

Notably, our asset-based proxy wealth index includes utility and sanitation variables, which can have direct effects on health, hence making it difficult to separate out indirect effects on health, via improved living conditions, from direct ones. Furthermore, a distinction should be made between variables that may be determinants of wealth, such as means of production, communication or transport, and those that are purely indicators of wealth, such as certain leisure goods [18]. Where quantifying the extent of inequality is the major goal, the concentration index and its associated concentration curve may be used $[39,40]$. Alternative approaches to measuring wealth, for example participatory wealth ranking (PWR), may be borrowed from development studies or from econometrics, potentially providing new insight for public health researchers [41].

An important drawback of the household survey method employed in our study is that the population sample did not include migrant populations, who tend to be the most poor and socially disadvantaged households in society [42], or information on informal remittances from temporary migrating household members [31]. Furthermore, the census data employed were obtained one year before our survey, and may have become inaccurate in the fast-changing living 
environment of contemporary P.R. China. Finally, compliance in the peri-urban setting was considerably lower than in the rural setting (70\% vs. $88 \%$ ) and no further information was available on non-compliant individuals for comparison [43]. Including the migrant population may have significantly altered the patterns emerging from our aggregated data and the apparently wide systemic rural to peri-urban gap [17].

While it is beyond the scope of this paper to comprehensively explore the factors behind the disparities both within and between settings, we call upon further research into the complex interactions between these and other assets such as human capital, public capital and land assets $[44,45]$. This would help to establish the driving forces of the observed differences between direct and proxy measures of wealth and to further examine how these differences impact on health service utilization, research and health policy $[44,45]$. Improved living conditions and diminished inequality gaps are not only important as distal and proximal determinants of health, but are also vital factors for national and regional sociopolitical stability [29]. Closing the rural to urban gap in particular is currently a top policy priority in P.R. China, with the $11^{\text {th }}$ Five Year Plan (2006-2010) having introduced the "Building a Socialist New Countryside" campaign [46]. In order to monitor and evaluate this campaign, however, it is crucial to have a time- and cost-effective appraisal of relative SEP [47]. This paper supports the use of the asset-based index as a proxy measure of wealth, with weights derived from either PCA or PAF, although we recommend caution when comparing aggregated data from various settings. Given the renewed interest in the role of inequalities on economic inefficiency [48], and the important role of P.R. China in achieving the Millennium Development Goals (MDGs) [49], it is conceivable that these methods will be of use in numerous other applications, as well as in other geographical locations.

\section{Appendix Definitions of economics and statistics terms used in this paper \\ Anti-image correlation matrix}

A matrix containing the negatives of the partial correlation coefficients. Most of the off-diagonal elements should be small in a good factor model.

\section{Asset}

An item of ownership convertible into cash.

\section{Bartlett's test of sphericity}

A method to test whether the correlation matrix is an identity matrix, which would indicate that the factor model is inappropriate.

\section{Cronbach's coefficient $\alpha$}

A method of assessing the internal consistency, or reliability, of a set of items, where $\left[\left(1-\alpha^{2}\right) \times 100\right]$ indicates the percent of variance in the items that could be attributed to measurement error.

\section{Durables}

Manufactured products such as an automobile or a household appliance that can be used over a relatively long period without being depleted or consumed.

\section{Eigenvalue}

The scalar of the associated eigenvector, indicating the amount of variance explained by each PC or each PF.

\section{Eigenvector}

A vector that results in a scalar multiple of itself when multiplied by a matrix. It corresponds to the weights in a linear transformation when computing PCA and PAF.

\section{Kaiser-Meyer-Olkin (KMO)}

A measure of sampling adequacy which tests whether the partial correlations among items are small.

\section{Kruskal-Wallis}

A non-parametric method for testing equality of population medians among groups.

\section{Peri-urban}

Immediately adjoining an urban area; between the suburbs and the countryside.

\section{Principal axis factoring (PAF)}

A data reduction technique which uses squared multiple correlations as initial estimates of the communalities. The communalities are entered into the diagonals of the correlation matrix before factors are extracted from the matrix, allowing the variance of each item to be a function of both item communality and non-zero unique item variance.

\section{Principal components analysis (PCA)}

A data reduction technique using the principle components model. It assumes that components are uncorrelated and that the communality of each item sums to one for all components, therefore implying that each item has zero unique variance.

\section{Rotation}

Turning the reference axes of the factors about their origin in order to achieve a simpler and theoretically more meaningful factor solution than is produced by the unrotated factor solution; the positions of the items 
are fixed in geometric space while the factor axes are rotated through specified angles.

\section{Socio-economic position (SEP)}

An aggregate concept that includes both resource-based and prestige-based measures. Resource-based measures refer to material and social resources and assets, including income, wealth, and educational credentials. Prestige-based measures refer to individuals rank or status in a social hierarchy, typically evaluated with reference to peoples' access to, and consumption of, goods, services and knowledge, as linked to their occupational prestige, income, and educational level.

\section{Utility}

A public service such as plumbing, electricity or railroad line.

\section{Additional material}

Additional file 1: Step-by-step procedure for generation of assetbased wealth indices. A step-by-step procedure for the generation of asset-based wealth indices, as used in this study.

\section{Acknowledgements}

The authors would like to thank all study participants. We thank colleagues from the Hunan Institute of Parasitic Diseases and the local antischistosomiasis control stations who were involved in this study. Penelope Vounatsou and Kylie-Ann Mallitt are acknowledged for statistical advice. This study received financial support from the National Health and Medical Research Council (Australia)/Wellcome Trust (UK) (ICRG Award) (DPM, YSL and GMW), the University of Queensland (GR) and the Swiss National Science Foundation through project no. PBBSB-109011 (GR) and PPOOB102883 and PPOOB-119129 (JU). JB is the recipient of a Northcote Graduate Scholarship.

\section{Author details \\ 'Queensland Institute of Medical Research, P.O. Royal Brisbane Hospital, Brisbane 4029, Queensland, Australia. ${ }^{2}$ School of Population Health, University of Queensland, Herston Road, Brisbane 4029, Queensland, Australia. ${ }^{3}$ Centre for Non-Traditional Security Studies, S. Rajaratnam School of International Studies, Nanyang Technological University, Nanyang Avenue, Singapore. ${ }^{4}$ Department of Global Health and Development, London School of Hygiene and Tropical Medicine, 15-17 Tavistock Place, London WC1 H 9SH, UK. ${ }^{5}$ Hunan Institute of Parasitic Diseases, Huabanqiao Road, Yueyang 414000, China. ${ }^{6}$ School of Public Health, Central South University, Changsha 410083, China. ${ }^{7}$ Department of Epidemiology and Public Health, Swiss Tropical and Public Health Institute, P.O. Box, CH-4002 Basel, Switzerland. ${ }^{8}$ University of Basel, P.O. Box, CH-4003 Basel, Switzerland. ${ }^{9}$ Département Environnement et Santé, Centre Suisse de Recherches Scientifiques en Côte d'Ivoire, 01 BP 1301, Abidjan 01, Côte d'Ivoire.}

\section{Authors' contributions}

$\mathrm{JB}$ was involved in the study design and in the implementation and COordination of the fieldwork, analyzed the data and drafted the manuscript. DPM, YSL and JU contributed to the study conception and design. ZYZ and LPY oversaw the fieldwork implementation. GMW assisted with the statistical analysis. YL, MYR, ZCL and JZ ran the household surveys in Wuyi and Laogang. GR supervised JB, contributed to the study conception, design, and implementation in the field. All authors were involved in critical revision of the manuscript and read and approved the final manuscript.

\section{Competing interests}

The authors declare that they have no competing interests.

Received: 26 March 2010 Accepted: 3 September 2010

Published: 3 September 2010

\section{References}

1. Krieger N: A glossary for social epidemiology. J Epidemiol Community Health 2001, 55(10):693-700.

2. McDonough P, Sacker A, Wiggins RD: Time on my side? Life course trajectories of poverty and health. Soc Sci Med 2005, 61(8):795-808.

3. Adler NE, Boyce T, Chesney MA, Cohen S, Folkman S, Kahn RL, Syme SL: Socioeconomic status and health. The challenge of the gradient. Am Psychol 1994, 49(1):15-24.

4. Regidor E: Social determinants of health: a veil that hides socioeconomic position and its relation with health. J Epidemiol Community Health 2006, 60(10):896-901.

5. Armstrong Schellenberg J, Victora CG, Mushi A, de Savigny D, Schellenberg D, Mshinda H, Bryce J, for the Tanzania IMCI MCE baseline household survey study group: Inequities among the very poor: health care for children in rural southern Tanzania. Lancet 2003, 361(9357):561-6.

6. Xin M, Gregory R, Wang YJ: Poverty, inequality, and growth in urban China, 1986-2000. J Comp Econom 2005, 33(4):710-29.

7. Sicular T, Yue X, Gustafsson B, Shi L: The urban-rural income gap and inequality in China. Rev Income Wealth 2007, 53(1):95-128.

8. Kanbur R, Zhao XB: Which regional inequality: rural-urban or coastinland? An application to China. J Comp Econom 1999, 27(4):686-701.

9. Rutstein SO, Johnson K: DHS Comparative Reports 6: The DHS Wealth Index. ORC Macro MEASURE DHS, Calverton, Maryland, USA 2004.

10. Filmer D, Pritchett LH: Estimating wealth effects without expenditure data-or tears: an application to educational enrolments in states of India. Demography 2001, 38(1):115-32.

11. Onwujekwe O, Hanson K, Fox-Rushby J: Some indicators of socioeconomic status may not be reliable and use of indices with these data could worsen equity. Health Econ 2006, 15(6):639-44.

12. McKenzie DJ: Measuring inequality with asset indicators. J Popul Econ 2004, 18(2):229-60.

13. Montgomery MR, Gragnaloti M, Burke K, Paredes E: Measuring living standards with proxy variables. Demography 2000, 37(2):155-74.

14. Ferguson B, Tandon A, Gakidou E, Murray CJL: Estimating permanent income using indicator variables. World Health Organization, Geneva 2002.

15. Pett MA, Lackey NR, Sullivan JJ: Making sense of factor analysis: the use of factor analysis for instrument development in health care research. Thousand Oaks, CA: Sage Publications 2003.

16. Sahn DE, Stifel D: Exploring alternative measures of welfare in the absence of expenditure data. Rev Income Wealth 2003, 49(4):463-89.

17. Falkingham J, Namazie C: Measuring health and poverty: a review of approaches to identifying the poor. London: DFID Health Systems Resource Centre 2002

18. Houweling TA, Kunst AE, Mackenbach JP: Measuring health inequality among children in developing countries: does the choice of the indicator of economic status matter? Int J Equity Health 2003, 2:8.

19. Li YS, Ross AGP, Yu DB, Li Y, Williams GM, McManus DP: An evaluation of Schistosoma japonicum infections in three villages in the Dongting Lake region of China I: prevalence, intensity and morbidity before the implementation of adequate control strategies. Acta Trop 1997, 68(1):77-91

20. Landis JR, Koch GG: The measurement of observer agreement for categorical data. Biometrics 1977, 33(1):159-74.

21. Feng W, Mason A: Demographic dividend and prospects for economic development in China. United Nations Expert Group Meeting on Social and Economic Implications of Changing Population Age Structures 2005.

22. Fan SG, Zhang XB, Robinson S: Structural change and economic growth in China. Rev Dev Econ 2003, 7(3):360-77.

23. Wan GH, Ming $L$, Zhao $C$ : The inequality-growth nexus in the short- and long-run: empirical evidence from China. J Comp Econ 2006, 34(4):654-67.

24. Wei YD: Regional inequality in China. Pro Hum Geogr 1999, 23(1):49-59.

25. Ying LG: Understanding China's recent growth experience: a spatial econometric perspective. Ann Reg Sci 2003, 37(4):613-28. 
26. Wan GH, Zhou ZY: Income inequality in rural China: regression-based decomposition using household data. Rev Dev Econ 2005, 9(1):107-20.

27. Wan GH: Understanding regional poverty and inequality trends in China: methodological issues and empirical findings. Rev Income Wealth 2007, 53(1):25-34.

28. Kanbur R, Zhang XB: Fifty years of regional inequality in China: a journey through central planning, reform, and openness. Rev Dev Econ 2005, 9(1):87-106.

29. Yuen TK: Factor decomposition of Chinese rural income inequality: new methodology, empirical findings and policy implications. J Comp Econ 1998, 26(3):502-28.

30. Yang DT, Fang C: The political economy of China's rural-urban divide. Centre for Research on Economic Development and Policy Reform Working Paper 62, Stanford University 2000.

31. Lindelow M: Sometimes more equal than others: how health inequalities depend on the choice of welfare indicator. Health Econ 2006, 15(3):263-79.

32. Cortinovis I, Vella V, Ndiku J: Construction of a socio-economic index to facilitate analysis of health data in developing countries. Soc Sci Med 1993, 36(8):1087-97.

33. Tandon A, Murray CJL, Salomon J, King G: Statistical models for enhancing cross-population comparability Global Programme on Evidence for Health Policy Discussion Paper No. 42. World Health Organization 2001.

34. Howe LD, Hargreaves JR, Huttly SRA: Issues in the construction of wealth indices for the measurement of socio-economic position in low-income countries. Emerg Themes Epidemiol 2008, 5(3).

35. Velicer WF, Eaton CA, Fava JL: Construct explication through factor or component analysis: a review and evaluation of alternative procedures for determining the number of factors or components. In Problems and Solutions in Human Assessment. Edited by: Goffin RD, Helmes E. Boston: Kluwer; 2000:

36. Vyas S, Kumaranayake L: Constructing socio-economic status indices: how to use principal components analysis. Health Policy Plan 2006, 21(6):459-68.

37. Lai DJ: Temporal analysis of human development indicators: principal component approach. Soc Indic Res 2000, 51(3):331-66.

38. Bollen KA, Glanville JL, Stecklov G: Economic status proxies in studies of fertility in developing countries: does the measure matter? Pop Stud 2002, 56(1):81-96.

39. The concentration index. Quantitative Techniques for Health Equity Analysis-Technical Note 72003.

40. Measuring living standards: household consumption and wealth indices. Quantitative Techniques for Health Equity Analysis-Technical Note 42003.

41. Hargreaves JR, Morison LA, Gear JSS, Kim JC, Makhubele MB, Porter JDH, Watts C, Pronyk PM: Assessing household wealth in health studies in developing countries: a comparison of participatory wealth ranking and survey techniques form rural South Africa. Emerg Themes Epidemiol 2007, 4(4).

42. Nguyen PB, Hill PS: The role of temporary migration in rural household economic strategy in a transitional period for the economy of Vietnam. Asian Popul Stud 2008, 4(1):57-75.

43. Allen A: Environmental planning and management of the peri-urban interface: perspectives on an emerging field. Environ Urban 2003, 15(1):135-48.

44. Gonzalez C, Houweling TAJ, Marmot MG, Brunner EJ: Comparison of physical, public and human assets as determinants of socioeconomic inequalities in contraceptive use in Colombia-moving beyond the household wealth index. Int J Equity Health 2010, 9:10.

45. Moser C, Felton A: The construction of an asset index measuring asset accumulation in Ecuador. Working Paper 87 Chronic Poverty Research Center 2007.

46. Fan CC: China's eleventh five-year plan (2006-2010): from "getting rich first" to "common prosperity". Eurasian Geogr Econ 2006, 47(6):708-23.

47. Wagstaff A, Paci P, vanDoorslaer E: On the measurement of inequalities in health. Soc Sci Med 1991, 33(5):545-57.

48. Kakwani N, Wagstaff A, vanDoorslaer E: Socioeconomic inequalities in health: measurement, computation, and statistical inference. J Econom 1997, 77(1):87-103.

49. Millennium Development Goals, China's Progress. United Nations Country Team in China 2004. doi:10.1186/1742-7622-7-7

Cite this article as: Balen et al:: Comparison of two approaches for measuring household wealth via an asset-based index in rural and periurban settings of Hunan province, China. Emerging Themes in Epidemiology $20107: 7$

\section{Submit your next manuscript to BioMed Central and take full advantage of:}

- Convenient online submission

- Thorough peer review

- No space constraints or color figure charges

- Immediate publication on acceptance

- Inclusion in PubMed, CAS, Scopus and Google Scholar

- Research which is freely available for redistribution

Submit your manuscript at www.biomedcentral.com/submit
C) Biomed Central 